\title{
Cadeia agroindustrial e transmissão de preços do algodão ao consumidor brasileiro
}

\author{
Agro-industrial cotton chain and price transmission to the brazilian \\ consumer
}

\begin{abstract}
Lucilio Rogerio Aparecido Alves ${ }^{1}$ (D), André Luis Ramos Sanches² (iD, Mauro Osaki² (D), Geraldo Sant'Ana de Camargo Barros ${ }^{2}$ (1), Andréia Cristina de Oliveira Adami² (1),
\end{abstract}

${ }^{1}$ Departamento de Economia, Administração e Sociologia, Centro de Estudos Avançados em Economia Aplicada (CEPEA), Escola Superior de Agricultura "Luiz de Queiroz" (ESALQ), Universidade de São Paulo (USP), Piracicaba (SP), Brasil. E-mail: Iralves@usp.br

${ }^{2}$ Centro de Estudos Avançados em Economia Aplicada (CEPEA), Escola Superior de Agricultura "Luiz de Queiroz" (ESALQ), Universidade de São Paulo (USP), Piracicaba (SP), Brasil. E-mails: andre.sanches@cepea.org.br; mosaki@usp.br; gscbarro@usp.br; adami@cepea.org.br

Como citar: Alves, L. R. A., Sanches, A. L. R., Osaki, M., Barros, G. S. A. C., \& Adami, A. C. O. (2021). Cadeia agroindustrial e transmissão de preços do algodão ao consumidor brasileiro. Revista de Economia e Sociologia Rural, 59(3), e232806. https://doi.org/10.1590/1806-9479.2021.232806

Resumo: Este trabalho tem dois objetivos principais. Em primeiro lugar, analisar o fluxo de transações ao longo da cadeia agroindustrial do algodão, identificando todas as etapas desde a compra dos insumos, seguida de produção agrícola, processamento, incluindo usos industriais da fibra e do caroço de algodão. Em segundo lugar, por meio de modelos aplicados de séries temporais, identificar a direção e a intensidade de transmissão de choques nos preços da fibra de algodão sobre os preços de roupas ao consumidor final. O algodão em caroço passa pelo beneficiamento, gerando os coprodutos caroço, fibrilha e fibra. O caroço é direcionado para ração animal, esmagamento e/ou deslintamento. A fibrilha tem usos industriais. A fibra de algodão é a que se adiciona maior valor agregado, sendo a fiação o primeiro elo da indústria têxtil, seguindo, em conjunto com fibras sintéticas, para tecelagem, malharias ou aviamentos, acabamentos, confecções, obtendo os vestuários e acessórios, ou linha cama, mesa e banho ou mesmo produtos técnicos, sacaria etc., que são vendidos nos mercados atacadistas e varejistas. O que se busca descobrir é como os avanços na eficiência na produção do algodão chegaram ao consumidor brasileiro. Trata-se de avaliar, ao longo do tempo, a transmissão de preços da pluma sobre preços de fios, tecelagem, vestuário e roupas no varejo. São usados dados de janeiro de 2000 a dezembro de 2018. Os resultados mostraram maior relação do preço da pluma com preços de fios e baixo impacto sobre elos seguintes. Entende-se que a pouca inter-relação de preços do algodão com os preços dos demais produtos da cadeia têxtil é resultado dos expressivos volumes e valores das importações de fibras sintéticas e de manufaturados.

Palavras-chave: cadeia têxtil, inflação, choques de preços, vetores autorregressivos.

Abstract: This paper has two main objectives. Firstly, to analyze the flow of transactions in the cotton value chain, identifying all steps from the purchase of inputs, followed by agricultural production, processing, including industrial uses of fiber and cottonseed. Secondly, to identify, through applied time series models, the direction and speed of transmission of shocks in cotton fiber prices over clothing prices to the final consumer. Seed cotton undergoes processing, generating cottonseed, cotton fiber, fibril, and fiber by-products. The cottonseed is intended for animal feed, crushing, and/or delinting. Cotton fiber has industrial uses and is one that adds the most added value. Spinning is the first link of the textile industry, following, together with synthetic fibers, to produce yarn, to weaving, knitting, clothing, obtaining the garments and accessories, or bed, table, and bath line or even products, bags, etc., which are sold in the wholesale and retail markets. Then, we want to understand how advances in efficiency in cotton production reached the Brazilian consumer. It is about evaluating, over time, the transmission of prices of the feather over the prices of yarns, weaving, clothing, and clothing at retail. Data from January 2000 to December 2018 are used. The results showed a greater relationship between 
cotton fiber price and yarn prices and a low impact on subsequent links. It is understood that the low interrelation of cotton prices with the prices of other products in the textile chain is the result of the significant volume and value of imports of synthetic fibers and manufactured products.

Keywords: textile chain, inflation, price shocks, autoregressive vectors.

\section{INTRODUÇÃO}

A produção de algodão no Brasil cresceu de forma expressiva nos últimos anos, não tendo ocorrido o mesmo com o consumo interno. Como resultado, os excedentes domésticos (disponibilidade interna menos consumo doméstico) se elevaram, possibilitando que as exportações tivessem forte crescimento, o que foi viabilizado também pela qualidade do produto brasileiro, aumentando sua participação nas transações internacionais.

Mesmo com o crescimento das exportações de fibras de algodão, o valor das exportações subtraído do valor das importações totais indica que a cadeia têxtil se mostra como uma das mais deficitárias na economia brasileira, devido ao crescente consumo interno de têxteis e manufaturados atendido pela expansão das importações. Segundo dados de Brasil (2020), desconsiderando-se as transações de fibras, em 2019 as importações superaram as exportações em 873,2 mil toneladas, equivalentes a um déficit de US\$ 3,6 bilhões.

Entre os anos-safras 2000/01 e 2018/19, a produção brasileira de algodão em pluma cresceu a uma taxa média de 4,4\% ao ano (a.a.), chegando a 2,73 milhões de toneladas, um recorde (Companhia Nacional de Abastecimento, 2019), e o Brasil se posiciona como o quarto maior produtor mundial (United States Department of Agriculture, 2019). No mesmo período, o consumo interno de algodão em pluma decresceu a 1,4\% a.a., passando de um consumo médio superior a 900 mil toneladas por ano na primeira década do século XXI para cerca de 700 mil na segunda década, sendo considerado o sétimo maior consumidor mundial.

Dada, portanto, essa falta de competitividade industrial na cadeia do algodão, os excedentes internos de matéria-prima foram aumentando, possibilitando ao Brasil se posicionar como o segundo maior exportador mundial, perdendo apenas para os Estados Unidos (United States Department of Agriculture, 2019). Entretanto, o país não tem conseguido ter o mesmo êxito no tocante à agregação de valor nas suas exportações. Entre os anos-safras 2000/01 e 2018/19, as exportações brasileiras cresceram a uma taxa média de $12 \%$ a.a., e atingiram 1,6 milhão de toneladas nesse último ano-safra (Companhia Nacional de Abastecimento, 2019). Apesar de todo o dinamismo observado na produção agrícola de algodão em pluma, que é uma das principais matérias-primas para a cadeia têxtil brasileira e mundial, seus manufaturados passaram a ser adquiridos cada vez mais do mercado externo.

Segundo o Instituto de Estudos e Marketing Industrial (2018), a estrutura da cadeia produtiva e de distribuição têxtil e de confecção se inicia com as compras de fibras e filamentos, as quais podem ser naturais, vegetais ou pelos, ou químicas (em que se encaixam as artificiais e sintéticas). Nota-se, a propósito, que as deficiências ligadas à indústria à base de fibras naturais também se estendem à própria fabricação de fibras artificiais, insumo de igual importância na fase industrial da cadeia produtiva. Segundo dados da Associação Brasileira de Produtores de Fibras Artificiais e Sintéticas (2019), a fabricação de fibras artificiais (raiom acetato e raiom viscose) e sintéticas (náilon, elastômeros, poliéster e acrílico), entre 2003 e 2018, decresceu a uma taxa de 4,0\% a.a., mas o consumo aparente aumentou a 1,4\% a.a., em média. Consequentemente, as importações de fibras artificiais e sintéticas também passaram a atender a demanda interna, com volumes crescendo a uma taxa média de $6,1 \%$ a.a.

Para se diagnosticar devidamente a interação entre a produção brasileira de algodão em pluma e da cadeia têxtil, e seus impactos sobre o segmento de vestuário e artigos têxteis ao consumidor, este trabalho objetiva contribuir para o entendimento do fluxo de transações ao longo da cadeia agroindustrial do algodão, ou seja, seu de Sistema Agroindustrial (SAG), identificando todas as etapas desde a compra de insumos, produção agrícola, processamento, usos industriais da fibra e do caroço de algodão, de modo a caracterizar as ramificações das transações entre elos das (agro)indústrias e a transmissão de choques de preços da unidade agrícola para os demais segmentos da cadeia. Não há na literatura a 
descrição do fluxo de transações agregadas desta cadeia produtiva, sendo esta uma primeira contribuição esperada do trabalho, permitindo, também, trabalhos adicionais.

Buscar-se-á, então, por meio de modelos econométricos de séries temporais, identificar a magnitude, a intensidade e a velocidade de transmissão de choques nos preços da fibra de algodão sobre os preços de roupas ao consumidor final. Os preços de algodão em pluma tiveram quedas expressivas entre os anos 2008 e 2009, seguido de altas mais expressivas até 2011. Nos anos seguintes, novas quedas foram observadas, mas a sustentação recente da produção de algodão no Brasil foi dada por preços mais atrativos, o qual elevou a rentabilidade da cultura e a competitividade agrícola perante culturas concorrentes em área. Porém, a maior parte da produção foi exportada. Questiona-se, portanto, de que forma e em que intensidade essas oscilações de preços chegam até o consumidor final, em um ambiente de necessidade cada vez maior de importações de fibras artificiais e de produtos finais manufaturados.

\section{EVOLUÇÃO, FLUXO DE TRANSAÇÕES E TRANSMISSÃO DE PREÇOS}

Nesta seção, analisam-se a evolução da cadeia produtiva do algodão brasileiro, suas relações comerciais e os reflexos sobre o consumidor final brasileiro. Importa, porém, antes, ter em conta que a produção brasileira de algodão passou por crises expressivas durante a década de 1980 e a primeira metade da década de 1990, com consequente redução de área e produção (Figura 1), que coincide com a abertura comercial para a cadeia produtiva. Naqueles períodos, as produções se concentravam no Sul e Sudeste do país, a demanda pela pluma era superior à produção interna e o Brasil era um dos principais importadores mundiais (United States Department of Agriculture, 2019). A partir da segunda metade da década de 1990, o cultivo de algodão se expandiu para o cerrado brasileiro, incialmente para o estado de Goiás, depois para o de Mato Grosso e, posteriormente, para o oeste do estado da Bahia, que se tornaram os principais estados produtores. Com excedente interno, em decorrência da estagnação da agroindústria têxtil, as exportações foram ganhando ritmo a partir dos anos 2000, evidenciando a competitividade da parte agrícola da cadeia. Além da migração da área de produção, o sistema produtivo também se modificou em relação àquele observado nas antigas regiões tradicionais, com maior tecnificação da produção, desde a fase de plantio até a fase de colheita.

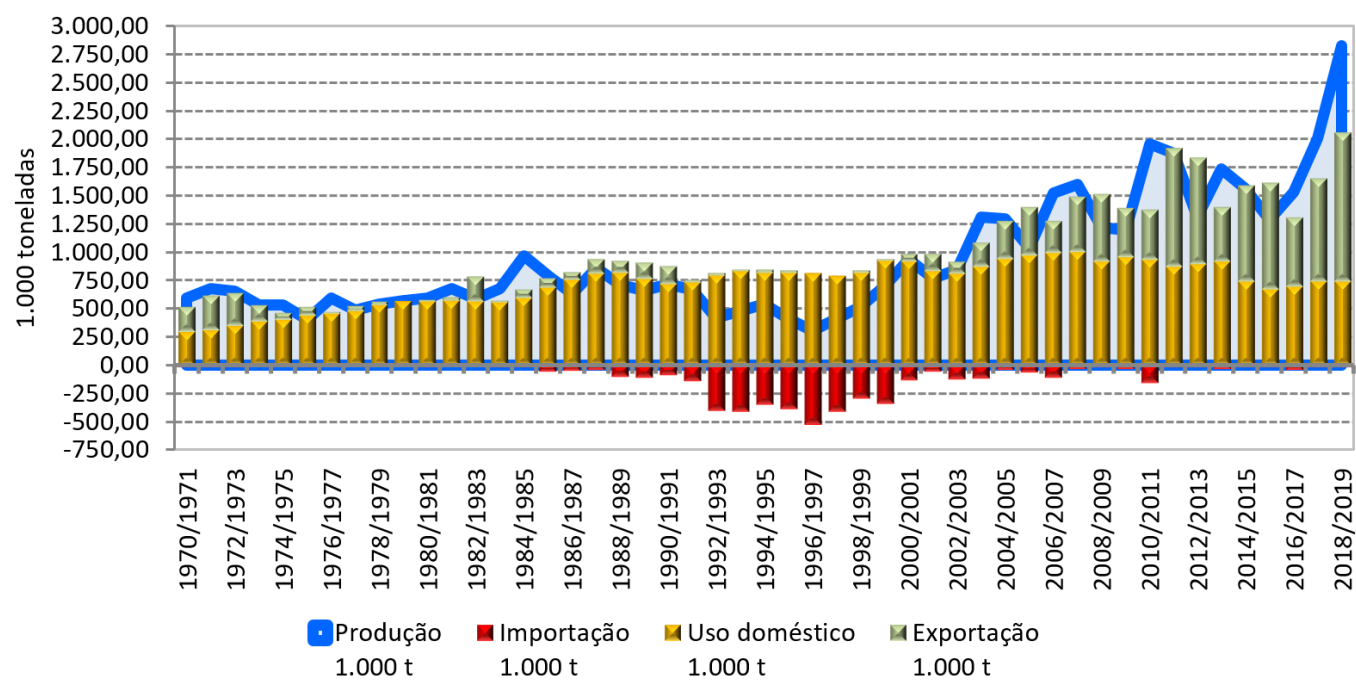

Figura 1. Evolução da produção, importação, consumo doméstico e exportação de algodão em pluma no Brasil, entre 1970/71 e 2018/19. Fonte: United States Department of Agriculture (2019).

A evolução da cultura do algodão até a década de 1970 é apresentada e analisada em detalhes em Freire et al. (1980), que buscaram descrever a contribuição da pesquisa para o desenvolvimento da cultura algodoeira no Brasil. Os autores apontaram que naquele período 
a cultura se mostrava relativamente rentável no Centro-Sul do país, mas que a queda da receita líquida contribuía para redução da produção interna. Conjuntamente, a perda de área era resultado da expansão do cultivo da soja, que se mostrava ainda mais rentável, além de que os preços mínimos governamentais eram inferiores aos custos de produção, em um ambiente de custos de produção crescentes.

Os aspectos relacionados à economia da produção na cultura do algodão também foram analisados por Rochelle \& Ferreira Filho (1999), com base em dados de 1975 a 1998. Os resultados mostraram que as despesas com mão de obra representaram a maior parcela dos custos de produção, sendo a demanda por mão de obra a mais sensível a variações no preço, uma vez que a colheita algodão era realizada manualmente - o estudo focou em dados para o estado de São Paulo.

Vários trabalhos analisaram as mudanças estruturais na cadeia produtiva do algodão. No final da década de 1990, Gonçalves (1997) analisou a crise do algodão brasileiro pósabertura dos anos 1990 e as condicionantes da retomada da expansão em bases competitivas. Da mesma forma, a transformação do mercado brasileiro de algodão e a influência de políticas comerciais foram analisadas por Barbosa (1996), considerando dados desde início da década de 1970. A autora apontou os impactos da abertura comercial sobre a cadeia, já sinalizando que as exportações de pluma poderiam ser uma alternativa para a retomada do crescimento da produção agrícola.

A evolução histórica da cadeia produtiva, com destaque para os períodos de crises nas últimas décadas do século XX e sua retomada em bases competitivas, foi tratada por Costa \& Bueno (2004). O trabalho visa dar ênfase aos resultados do painel da Organização Mundial do Comércio (OMC), que questionava os altos subsídios concedidos pelo governo dos Estados Unidos a seus produtores.

Alves (2006) destacou que a expansão da produção de algodão a partir da década de 1990 decorreu de uma conjugação de fatores de ordem tecnológica (do lado da oferta) e mercadológica (do lado da demanda). A capacidade empresarial e empreendedora dos produtores brasileiros contribuiu para que o setor se organizasse e se transformasse numa "cotonicultura empresarial". O processo de redefinição institucional e os investimentos em pesquisa resultaram em saltos de produtividade, que se viabilizam graças às exportações, que moderavam as quedas de preços que, fatalmente, ocorreriam caso a expansão da produção ficasse represada no mercado interno. Modelos econômicos para aferir o crescimento do setor em termos de choques de oferta e de demanda apontaram que a produtividade da lavoura explica aproximadamente 1/3 do crescimento da produção e quase $25 \%$ da evolução da exportação de algodão do Brasil. Entretanto, variações de preços explicam cerca de $15 \%$ da produção. Além disso, configurado um cenário de rentabilidade, o setor tende a ajustar a área e a produção durante um período de uma década ou mais, num processo autorregressivo característico (Alves et al., 2008).

A competitividade da produção de algodão entre o Brasil e os Estados Unidos da América (EUA) foi analisada por Ferreira Filho et al. (2009) com base nos custos de produção agrícola, para a safra 2003/04. Segundo os resultados dos autores, o Brasil se mostrou mais competitivo, com alta produtividade, mas os custos considerados altos por hectare, indicando elevado risco da cultura, devido às margens estreitas e aos sunk cost. Houve menor produtividade para os EUA, com custos relativamente altos e margens negativas, induzindo os autores a concluírem que a sustentabilidade do setor algodoeiro nos EUA era totalmente dependente de ajuda governamental.

Brasil (2007) analisou a cadeia do algodão brasileiro, compreendendo a dinâmica histórica recente da produção agropecuária, identificando gargalos e potencialidades, para que pudessem recomendar linhas de ações adequadas para promover o desenvolvimento competitivo e sustentável da cotonicultura brasileira. Além de destacar o crescimento da produção no cerrado brasileiro, indicou a necessidade de uma política nacional para elevar a competitividade da produção de tecidos e confecções no Brasil.

Mais recentemente, Castro et al. (2017) analisaram o padrão de crescimento do Valor Bruto da Produção (VBP) do algodão herbáceo para o Brasil, com dados para o período de 1995 e 2015, enfatizando o contexto de estados como Bahia, São Paulo, Paraná, Mato Grosso do Sul, Mato Grosso e Goiás. Utilizando a metodologia de shift-share, os autores indicaram 
que o aumento do VBP é explicado principalmente por ganhos de produtividade, sendo que o efeito área mostrou-se relativamente inexpressivo para o crescimento do VBP. Já o efeito preço teve um papel predominantemente negativo sobre a expansão do VBP.

Uma visão mais agregada da estrutura de mercado e formação de preços na cadeia produtiva do algodão é apresentada em detalhes em Alves et al. (2018). Os autores apresentam uma visão das transações na cadeia produtiva do algodão, assim como a interrelação entre os preços domésticos e internacionais, cujo material foi a base para a construção das seções seguintes deste trabalho.

Para o setor industrial, Costa \& Rocha (2009) apresentaram um panorama nacional e internacional na década de 2000. Os autores mostraram a necessidade de desenvolver atividades inovativas como um instrumento fundamental para a estratégia competitiva das empresas dessa cadeia produtiva no Brasil. Essas ações ainda estão em pauta, especialmente em um contexto em que as transformações recentes da indústria têxtil mundial, derivadas da inserção de novos atores no comércio mundial de têxteis, oriundos principalmente de países asiáticos, que passaram a ofertar produtos mais baratos, provocando a reação dos produtores dos países europeus e dos Estados Unidos (Dias, 2014).

Nas subseções seguintes são apresentados detalhes sobre o fluxo de transações na cadeia produtiva do algodão e trabalhos que analisaram a transmissão de preços do algodão.

\subsection{Transações na cadeia produtiva do algodão}

O algodão se enquadra no conceito de fibra natural (Akil et al., 2011) e é a principal fibra vegetal utilizada pela indústria têxtil. As fibras naturais, de acordo com sua origem, também podem ser divididas entre animais e minerais, além das fibras vegetais, sendo que suas características e propriedades são apresentadas em Sanjay et al. (2018). Os usos e aplicações do algodão em caroço e seus derivados foram descritos e analisados por Desrochers \& Szurmak (2017).

Coleman \& Thigpen (1991) citam que o algodão é colhido na forma de algodão em caroço e requer o beneficiamento para separar a fibra e a semente. $O$ algodão em pluma (fibra) é a principal matéria-prima natural para indústria têxtil, o qual pode ser utilizado como única fibra em um tecido e/ou misturado com outras fibras naturais ou artificiais, para fornecer características especiais de desempenho a um tecido específico ou mesmo por considerações de custo. Inicialmente, as fibras são utilizadas na produção de fios; os fios são transformados em tecidos; os tecidos são acabados e depois transformados em produtos ao consumidor.

Vale considerar, segundo Coleman \& Thigpen (1991), que a indústria têxtil irá escolher o tipo de fibra que irá utilizar, baseando-se em desempenho técnico, nos preços relativos e, certamente, nas preferências dos consumidores. Os concorrentes mais diretos do algodão são as fibras de poliéster (sintéticas) e o raiom (artificiais).

Brasil (2007) indicou que entre os principais usos da fibra de algodão estão móveis, aplicações médicas, indústria automobilística e várias outras indústrias. Contudo, é na fiação com destino à indústria têxtil sua principal aplicação. Além disso, destaca que o fluxo de transações do algodão na cadeia têxtil é uma das mais complexas e longas, passando por inúmeras etapas desde a produção primária até o consumidor final. Da unidade agrícola, o algodão em caroço passa pelo beneficiamento, seguindo para a fiação e tecelagem.

A cadeia produtiva do algodão brasileiro foi descrita e mensurada financeiramente por Neves \& Pinto (2012). Os autores desagregaram a cadeia produtiva em três divisões: antes da fazenda, na fazenda e depois da fazenda. No segmento antes da porteira foram descritos os insumos, máquinas e implementos utilizados na produção. Na fazenda, ou segmento "dentro da porteira", foram mensurados os valores da produção da fibra, caroço e fibrilha. No segmento depois da fazenda ("fora da porteira"), foram considerados o esmagamento de caroço de algodão e o uso da pluma, sendo neste caso envolvidas a fiação, tecelagem, malharia e confecções.

Em nível mundial, a cadeia têxtil de confecções e vestuário foi descrita por Van Tot (2014), segregando nas etapas de produção agrícola; de fornecimento de matérias-primas naturais, artificiais e sintéticas; produção de bens intermediários, como tecidos fornecidos por empresas de tecelagem, tricô e tingimento; projetos e fabricação de produtos acabados por 
empresas de vestuário; exportação por intermediários comerciais; e marketing e distribuição. Construção de cadeia de valor têxtil seguindo essa linha, mas com mais detalhamentos, incluindo contratos, também foi apresentada por Martin (2014).

A cadeia produtiva têxtil mundial foi apresentada por Bevilacqua et al. (2014), em estudo que objetivou comparar os impactos ambientais relacionados à produção de fio de algodão desde a unidade agrícola, em um contexto de oferta de algodão por quatro empresas localizadas em quatro países diferentes (Egito, China, Índia e EUA). Entretanto, o autor não avançou nas discussões de todas as etapas do processo produtivo, principalmente nas etapas finais, até o consumidor final de têxteis.

Contudo, Perveen \& Arsalan (2014) apresentaram uma visão geral do gerenciamento da cadeia de suprimentos de algodão e seus processos, incluindo suas entradas e saídas. O foco dos autores eram os fatores de influência na cadeia produtiva e o uso de tecnologias de informação geográfica no gerenciamento da cadeia de suprimentos de algodão.

Com base nos trabalhos citados nesta seção, pretende-se descrever as relações entre os elos da cadeia produtiva do algodão brasileiro de modo a entender seu fluxo de transações entre a produção agrícola e o consumidor dos manufaturados. Na parte industrial, também será levada em consideração a estrutura apresentada em Associação Brasileira da Indústria Têxtil e de Confecção (2013) e em Alves et al. (2018), que detalham as etapas de fiação, tecelagem, malharia, beneficiamentos, confecções e os manufaturados finais.

\subsection{Transmissão de preços de algodão}

A transmissão de preços de algodão foi objetivo de análise de vários trabalhos. Coleman \& Thigpen (1991) especificaram um modelo econométrico para prever preços, produção e consumo para alguns dos principais participantes do mercado mundial de fibras, como China e Estados Unidos. O estudo envolveu o mercado mundial de fibras, mas a ênfase esteve voltada ao setor de algodão. No modelo ajustado pelos autores, o preço do algodão em nível mundial era determinado pelos estoques mundiais de algodão. A oferta foi calculada como resultado da produtividade e da área. O consumo de algodão foi derivado da participação do algodão no consumo total de fibra. Considerou-se a participação de algodão e fibras não celulósicas como funções dos preços do algodão e do poliéster; e o consumo total de fibra foi determinado pela renda, população e níveis gerais de preços. O suprimento de fibras não celulósicas em nível mundial foi estimado em função dos preços do poliéster e do petróleo bruto, enquanto o preço do poliéster foi estimado por equação de demanda invertida para a região do Resto do Mundo (presume-se que haja existências de fibras não celulósicas).

Entre os resultados dos modelos de previsão, Coleman \& Thigpen (1991) indicaram que para cada aumento de $1 \%$ na produção chinesa, o preço mundial do algodão cairia, em média, cerca de $1 \%$ e o preço do poliéster cederia $0,35 \%$. Já uma queda de $10 \%$ no preço do algodão nos Estados Unidos teria como efeito reduzir a produção americana em menos de 3\%, em média, e aumentar os preços mundiais em 3,7\%. Já simulações com alterações nos preços do petróleo indicaram que os preços do poliéster e do algodão reagiriam positivamente, mas que, em geral, o impacto nos mercados é pequeno.

A relação entre os preços do algodão e das fibras concorrentes também foi foco de estudo de Pan et al. (2006), visando analisar os efeitos da eliminação dos programas de subsídio de algodão dos EUA no mercado mundial de algodão. Usando como método um modelo de equilíbrio parcial para o mercado mundial de fibras, os autores concluíram que a remoção dos programas de subsídios americanos reduziria a oferta e as exportações do país e os preços mundiais do algodão aumentariam em aproximadamente $2 \%$ nos primeiros anos. O maior preço atrairia produções nos demais países, como Brasil e Austrália, levando a um ajustamento de preços nos anos seguintes.

Ainda no contexto internacional, estudo de Ozturk (2017), com dados de setembro de 2002 a dezembro de 2014, buscou verificar as integrações dos mercados domésticos de algodão da China, Brasil e Turquia com o mercado mundial de algodão, considerando também a cointegração entre os mercados e seus efeitos sobre o comércio mundial de algodão. Estimando elasticidades de transmissão de preços e taxas de câmbio e um modelo de equilíbrio parcial, os resultados do autor sinalizaram que a cointegração entre os 
mercados é fraca e a Lei do Preço Único ${ }^{1}$ não se aplica. Com isso, também descreveu que os movimentos da taxa de câmbio nos países pouco influenciam as transações de algodão no mercado mundial.

Para o Brasil, Barbosa et al. (2002) analisaram a elasticidade de transmissão de preços no mercado de algodão para o período de janeiro de 1985 até dezembro de 2000. Os autores verificaram que a Lei do Preço Único não era válida para o mercado brasileiro de algodão com os dados para o período em análise, uma vez que variações nos preços internacionais do algodão não eram totalmente transmitidas para os preços domésticos no Brasil. Além disso, chamaram atenção para o fato de que os resultados poderiam estar sendo influenciados pela intervenção governamental sobre o setor, observada entre 1985 e 1988, e pelas condições favoráveis para a importação de algodão entre 1990 e 1997.

Coelho (2004) analisou a integração de preços brasileiro e externo do algodão, com dados para o período entre 1982 e 2001. As conclusões apontam para uma perfeita integração entre os preços de algodão em pluma no Brasil e o preço internacional, representado pela série de preços de mercado futuro americano, com destaque para a década de 1990.

Com informações de preços para o período de 1998 a 2005, Alves \& Ferreira Filho (2006) chegaram a resultados semelhantes aos dos autores anteriores, mostrando a maior relação dos preços externos para os preços internos. Esta relação e seu detalhamento também foram apresentados em Ferreira Filho \& Alves (2006).

Utilizando dados para o período de 1986 a 2003, Cruz \& Maia (2008) estudaram o desempenho da cotonicultura brasileira pós-abertura comercial, separando o período em dois momentos: 1989-1995 e 1996-2003. O foco maior foram fatores de respostas às exportações brasileiras de algodão. Para ambos os períodos, a própria exportação foi o fator que mais explicou as variações a cada ano. Para o segundo período, a taxa de câmbio também se mostrou relevante.

Observa-se que todos os trabalhos analisaram a transmissão de preços de fibras entre diferentes países e/ou regiões produtoras. Entretanto, nenhum deles estimou e avaliou a transmissão de preços entre os diferentes elos da cadeia produtiva têxtil de forma agregada, especialmente com foco no Brasil, lacuna que este trabalho pretende preencher.

\section{MATERIAL E MÉTODOS}

De modo geral, a metodologia adotada neste trabalho segue o descritivo de Jonker \& Pennink (2010), especialmente no que se refere aos modelos conceituais. Para atender ao objetivo deste trabalho, de descrever o fluxo de transações da cadeia agroindustrial do algodão, identificando todas as etapas entre a compra de insumos, produção agrícola, processamento, usos industriais da fibra e do caroço de algodão, caracterizando as ramificações das transações entre elos das (agro)indústrias, são utilizadas como referência as metodologias aplicadas por Farina (1999), Zylbersztajn (2000) e Buainain \& Sousa Filho (2008). O fluxo será estruturado com referência aos trabalhos citados na seção 2.1, que descreveram as transações em contextos parciais da cadeia produtiva.

Para avaliar a direção, a intensidade e a velocidade de transmissão de choques nos preços da fibra de algodão sobre os preços de roupas ao consumidor final, foi estimado um modelo de Vetores Autorregressivos com Correção de Erros (VEC). Essa metodologia permite a obtenção de elasticidades de impulso para $k$ períodos à frente, possibilitando a avaliação do comportamento das variáveis (preços dos produtos da indústria têxtil) em resposta a choques (inovações) individuais não esperados em quaisquer das demais variáveis do sistema. A decomposição da variância dos erros de previsão, para $k$ períodos à frente, trata da análise da importância de cada choque (em cada variável do modelo) na explicação dos desvios dos valores observados das variáveis em relação à sua previsão realizada no início do período considerado.

\footnotetext{
${ }^{1}$ A Lei do Preço Único, preconiza que o preço de um determinado produto, avaliado em diferentes países produtores,
} desconsiderando-se custos de transporte e transação, deve ser idêntico quando avaliado na mesma moeda. 
Para ajustar o modelo VEC, inicialmente deve-se verificar a estacionariedade e a ordem de integração de cada uma das séries de preços (número de raízes unitárias), via teste ADFGLS proposto por Elliott et al. (1996) e também descrito em Enders (2014). Também foram analisados os testes denominados KPSS, propostos por Kwiatkowski et al. (1992). Em seguida, o número de vetores de cointegração para cada conjunto de séries de preços foi avaliado através do teste proposto por Johansen (1988), pois, no caso das variáveis serem integradas e cointegradas, termo(s) de correção de erro deve(m) ser utilizado(s) no modelo ajustado com as séries nas primeiras diferenças para recuperar os desvios de curto prazo, conforme proposto por Engle \& Granger (1987) e Johansen \& Juselius (1990). A ordem de defasagens do modelo VEC e a construção da matriz de relações contemporâneas foram definidas pela significância dos coeficientes estimados. Trata-se, portanto, de um modelo VEC na forma estrutural.

Os testes de raiz unitária e de cointegração foram realizados no software $\mathrm{R}^{\circledR}$. O Vetor Autorregressivo foi estruturado no software WinRats ${ }^{\circledR}$.

\subsection{Base de dados}

O modelo de transmissão de preços ajudará a definir a direção, intensidade e velocidade com que variações nos preços da pluma (matéria-prima) são transmitidas aos preços dos produtos de seus derivados ao longo dos elos da cadeia agroindustrial do algodão até que este efeito chegue ao consumidor final de roupas. Assim, será possível avaliar como choques nos preços de algodão em pluma impactarão os preços dos fios, depois os preços das tecelagens, em seguida os preços de vestuários, até os preços de roupas ao consumidor final, representado pelas variações do produto que compõem o Índice de Preços ao Consumidor Amplo (IPCA).

Os preços do algodão em pluma foram obtidos em Cepea/Esalq-USP (Universidade de São Paulo, 2019), enquanto os demais índices foram obtidos em FGV-Ibre (Fundação Getúlio Vargas, 2018), sendo que o subíndice do IPCA é calculado pelo Instituto Brasileiro de Geografia e Estatística (IBGE). Foram utilizados preços médios mensais para o período de análise de janeiro de 2000 a dezembro de 2018, com dados médios mensais. Com o objetivo de entender como choques de preços do produto agrícola são repassados para preços ao consumidor final de manufaturados, todas as séries foram consideradas em valores nominais, e, portanto, não foram deflacionadas.

\section{RESULTADOS E DISCUSSÃO}

Esta seção está subdividida em dois grandes tópicos. Na primeira subseção, descreve-se o fluxo de transações para a cadeia agroindustrial do algodão, ou seu Sistema Agroindustrial (SAG), identificando todas as etapas entre a compra de insumos, produção agrícola, processamento, usos industriais da fibra e do caroço de algodão, caracterizando as ramificações das transações entre elos das (agro)indústrias. Na segunda subseção, serão apresentadas as séries de dados e o modelo econométrico que visa identificar a direção, a intensidade e a velocidade de transmissão de choques nos preços da fibra de algodão sobre os preços de roupas ao consumidor final.

\subsection{Cadeia agroindustrial do algodão}

Esta subseção trata do detalhamento do fluxo da cadeia agroindustrial do algodão, que é apresentado na Figura 2. Conforme pode-se observar, os primeiros elos da cadeia produtiva são os relacionados às ofertas de insumos, máquinas e equipamentos para a produção agrícola. Do algodão colhido na fazenda, são gerados três principais produtos comerciais: a fibra (pluma), o caroço e a fibrilha. A fibrilha tem diferentes usos industriais, que em seguida são direcionados para o atacado, varejo, ou mesmo para a exportação.

O caroço de algodão pode ser utilizado como ração na alimentação de gado de corte ou de leite, ou mesmo para esmagamento. O caroço de algodão que alimenta o gado de leite contribui para a produção de leite, o qual segue para o laticínio, gerando o leite industrializado, leite em pó ou outros derivados de leite. Já o gado de corte segue para o abatedouro, resultando em cortes de carne e derivados e produtos industrializados. Todos esses produtos são 
direcionados para o atacado e depois para o varejo (consumidor final). Consideram-se, também, as possibilidades de exportação e/ou importação dos produtos finais.

$\mathrm{Na}$ esmagadora de caroço de algodão, pode ser realizado o deslintamento, obtendo o linter, o qual tem diferentes usos industriais. Se esmagados, geram-se torta ou farelo e óleo. A torta pode ser utilizada na ração animal ou mesmo na indústria de adubos. O óleo apresenta diferentes aplicações industriais, incluindo as alimentícias, ou mesmo na indústria de biodiesel. Nesta indústria, também são produzidos a glicerina e o próprio biodiesel, o qual é misturado ao óleo diesel para venda ao atacado e varejo.

Entretanto, o produto de maior valor mercadológico originado da produção de algodão é a pluma, que é utilizada especialmente pela indústria têxtil no mercado interno ou mesmo no mercado internacional. A indústria têxtil pode escolher entre outras fibras naturais, assim como por fibras artificiais e sintéticas. Como já citado por Coleman \& Thigpen (1991), a indústria têxtil irá escolher o tipo de fibra que vai utilizar com base em desempenho técnico, preços relativos e, certamente, no tipo de produto que irá atender as preferências dos consumidores.

$\mathrm{Na}$ indústria têxtil, as fibras serão utilizadas pelas fiações, visando obter fios e filamentos. Estes produtos, nacionais ou importados, são encaminhados para as indústrias que realizam a tecelagem. Nesse segmento, também há relações com indústrias de malharia de tecidos planos, assim como com indústrias de aviamentos, para que possam realizar os acabamentos.

O elo seguinte são as indústrias de confecções, que geram os produtos para vestuários e acessórios, assim como para produtos dos segmentos de cama, mesa e banho. Da confecção também são produzidos produtos técnicos, que envolvem inclusive sacaria, encerados, fraldas etc. Esses produtos finalizados são direcionados para os mercados atacadistas e/ou varejistas.

Um fato interessante é que em qualquer etapa da industrialização têxtil poderá haver exportação e/ou importação de qualquer produto. Este é um ponto-chave na indústria têxtil, em que os valores de importações superam os valores de exportações desde 2006 (Brasil, 2019). Este é um aspecto que certamente poderá afetar os resultados econométricos a serem tratados em seguida.

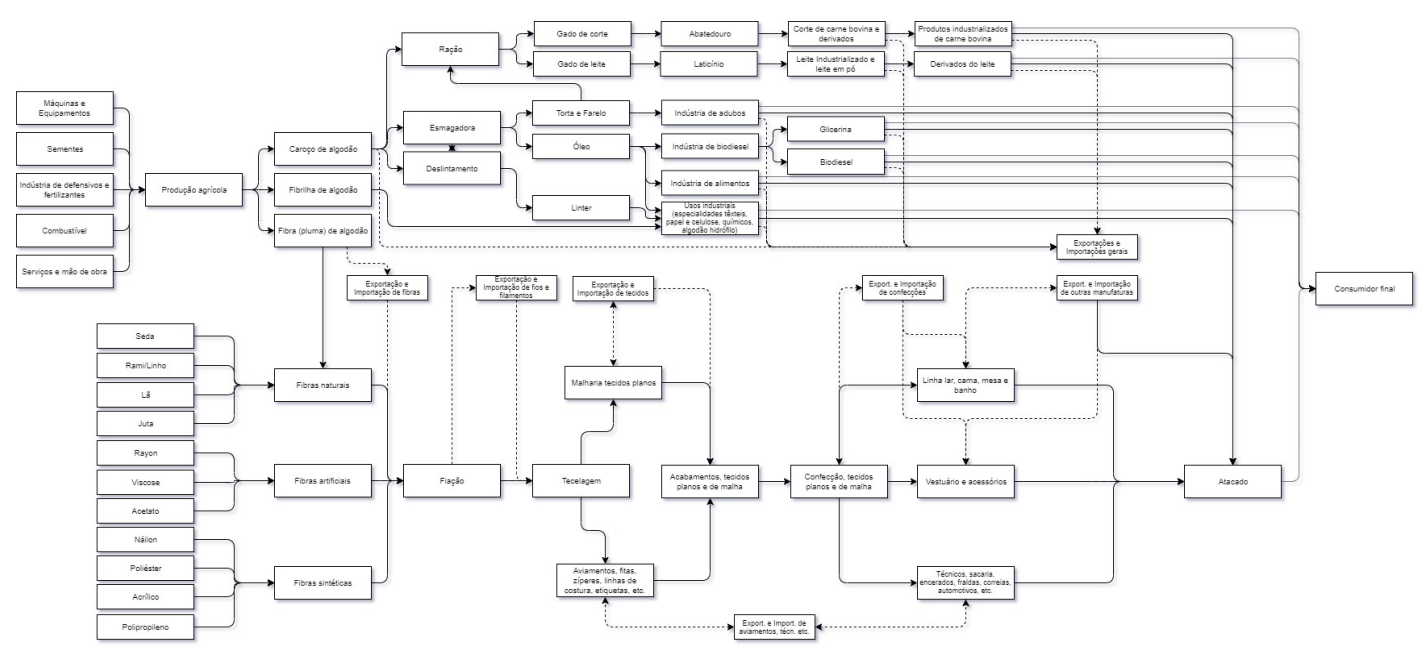

Figura 2. Cadeia agroindustrial do algodão: da unidade agrícola ao consumidor. Fonte: Elaborado pelos autores, com base nos autores e descrição da seção 2.1.

\subsection{Impactos dos preços do algodão em pluma sobre os preços de roupas no Brasil}

Com base nas informações da seção anterior e diante do objetivo de entender os impactos de choques de preços de algodão sobre os preços de roupas no varejo, considerouse o seguinte fluxo de transações na cadeia têxtil: 
As evoluções dos índices destes preços constam da Figura 3. Os preços do algodão em pluma e dos fios (se referem a preços de fios como um todo, não sendo possível identificar os preços apenas de fios de algodão) são os que apresentam oscilações mais expressivas no período sob análise, com destaque para os preços de algodão. A oferta de algodão em pluma tende a oscilar de forma mais expressiva, devido a impactos especialmente das condições climáticas, cujas oscilações se refletem nos preços. A oferta de fios passa pela produção industrial, sendo mais fácil seu ajustamento com a demanda. Nominalmente, os preços de algodão acumularam valorização de $253,27 \%$ no período de janeiro de 2000 a dezembro de 2018 , enquanto os preços dos fios se valorizaram 193,50\% no mesmo período.

Os preços das tecelagens apresentaram correlação expressiva com os preços dos fios e acumularam valorização de $205,84 \%$ no período em análise. Entretanto, chama atenção a menor correlação entre os preços de tecelagem e vestuário, com destaque para variações menos expressivas do vestuário. Entre janeiro de 2000 e dezembro de 2018, seus preços nominais aumentaram em cerca de $100 \%$. Esse resultado pode ser explicado em grande parte pelo significativo volume de importações no mesmo período de análise. Segundo o MDIC/Secex (Brasil, 2019), as confecções, envolvendo roupas e vestuários acabados, são os grupos de produtos mais deficitários na cadeia têxtil brasileira.

Porém, os preços de roupas no mercado varejista tiveram valorizações constantes e mais expressivas que os preços de vestuário como um todo. Nos 19 anos sob análise, seus preços nominais subiram $170 \%$. Observa-se, portanto, que as variações do produto agrícola são mais expressivas que as dos segmentos seguintes da cadeia agroindustrial do algodão, o que sugere que o mercado varejista praticamente não absorve choques expressivos vindos dos preços da matéria-prima agrícola.

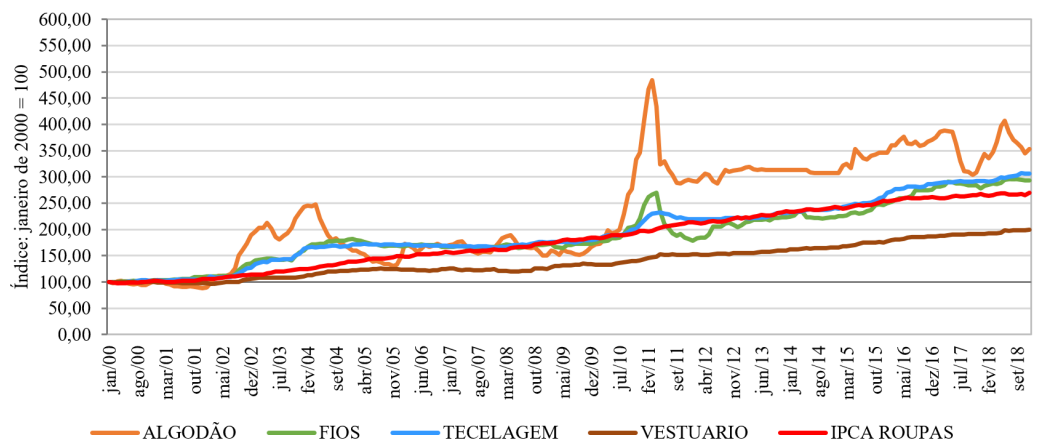

Figura 3. Evolução dos índices de preços nominais de algodão em pluma, de fios, de tecelagem, de vestuário e de roupas no varejo (IPCA roupas) no Brasil, jan./2000 a dez./2018. Fonte: Universidade de São Paulo (2019), Fundação Getúlio Vargas (2018).

Para cada uma das séries apresentadas na Figura 3, inicialmente foi investigada a estacionariedade a partir da implementação dos procedimentos propostos por Elliott et al. (1996), via teste DF-GLS. Os resultados do teste DF-GLS constam da Tabela 1, os quais indicam a presença de uma raiz unitária, ou não estacionariedade, nas séries. Quando analisadas a primeira diferença das séries, os resultados indicam a rejeição da hipótese nula (existência de raiz unitária) em todas as séries investigadas.

Tabela 1. Resultado dos testes de raiz unitária Dickey-Fuller Generalized Least Squares (DF-GLS) para as séries de preços

\begin{tabular}{cccccc}
\multirow{2}{*}{ Variável } & \multicolumn{2}{c}{ Em nível } & & \multicolumn{2}{c}{ Na primeira diferença } \\
\cline { 2 - 3 } \cline { 5 - 6 } Preço de algodão & Modelo 1 & Modelo 2 & & Modelo 1 & Modelo 2 \\
Índice de preços de fios & $-0,339$ & $-3,082$ & & $-4,358$ & $-4,471$ \\
Índice de preços de tecelagem & 1,714 & $-2,173$ & & $-5,011$ & $-5,365$ \\
Índice de preços de vestuário & 1,108 & $-2,125$ & & $-1,833$ & $-3,894$ \\
IPCA roupas & 1,918 & $-1,216$ & & $-1,554$ & $-3,182$ \\
& $-0,092$ & $-1,748$ & & $-0,649$ & $-5,339$
\end{tabular}

Fonte: Resultados da pesquisa. Modelo 1: na versão com constante, valores críticos a $1 \%=-2,58,5 \%=-1,95$. Modelo 2: na versão com constante e com tendência, valores críticos a $1 \%=-3,48$ e $5 \%=-2,89$. 
Adicionalmente, também foi investigada a estacionariedade com base nos testes de KPSS, conforme Kwiatkowski et al. (1992). Assim como o teste DF-GLS, os resultados indicaram que as séries têm uma raiz unitária (Tabela 2).

Tabela 2. Resultado dos testes KPSS de raiz unitária para as séries de preços

\begin{tabular}{|c|c|c|c|c|c|c|}
\hline \multirow{2}{*}{ Variável } & \multicolumn{2}{|c|}{$\begin{array}{c}\text { Modelo com } \\
\text { constante e tendência }\end{array}$} & \multicolumn{2}{|c|}{$\begin{array}{l}\text { Modelo com } \\
\text { constante }\end{array}$} & \multicolumn{2}{|c|}{$\begin{array}{c}\text { Modelo com séries } \\
\text { nas diferenças }\end{array}$} \\
\hline & $\begin{array}{c}\text { valor } \\
\text { estimado }\end{array}$ & *p-valor & $\begin{array}{c}\text { valor } \\
\text { estimado }\end{array}$ & ${ }^{\star}$ p-valor & $\begin{array}{c}\text { valor } \\
\text { estimado }\end{array}$ & *p-valor \\
\hline Preço de algodão & 0,172 & 0,146 & 2,959 & 0,463 & 0,032 & 0,463 \\
\hline $\begin{array}{l}\text { Índice de preços de } \\
\text { fios }\end{array}$ & 0,316 & 0,146 & 4,043 & 0,463 & 0,061 & 0,463 \\
\hline $\begin{array}{l}\text { Índice de preços de } \\
\text { tecelagem }\end{array}$ & 0,377 & 0,146 & 4,275 & 0,463 & 0,161 & 0,463 \\
\hline $\begin{array}{l}\text { Índice de preços de } \\
\text { vestuário }\end{array}$ & 0,303 & 0,146 & 4,525 & 0,463 & 0,129 & 0,463 \\
\hline IPCA roupas & 0,919 & 0,146 & 4,606 & 0,463 & 0,129 & 0,463 \\
\hline
\end{tabular}

Fonte: Resultados da pesquisa. * Valores críticos para um nível de significância de 5\%.

As análises de cointegração (Tabela 3), utilizadas para avaliar a relação de longo prazo entre as séries de preços, foram realizadas via testes do traço e de autovalor, os quais indicaram a presença de quatro vetores de cointegração. Assim, com base nos resultados dos testes de raiz unitária e cointegração, ajustou-se um modelo estrutural de Vetores Autorregressivos com Correção de Erros (VEC), levando em conta quatro vetores significativos de cointegração.

Além dos quatro vetores de cointegração, o modelo VEC foi ajustado, considerando-se como ordem de entrada das variáveis no modelo a apresentada na Tabela 1, ou seja, preço do algodão, preço do fio, preço do tecido, preço do vestuário, IPCA roupas. Para definir a matriz de relações contemporâneas, levou-se em conta que no mesmo mês apenas os preços de fios teriam impacto sobre os preços do algodão, pois espera-se que alterações nos preços de fios impactem a decisão de compra de pluma no mesmo mês.

Tabela 3. Resultado dos testes de cointegração de Johansen (1988) para as séries de preços na cadeia têxtil

\begin{tabular}{|c|c|c|c|c|c|c|c|c|}
\hline Vetores & \multicolumn{4}{|c|}{ Teste de máximo autovalor } & \multicolumn{4}{|c|}{ Teste do traço } \\
\hline $\mathbf{p}-\mathbf{r}$ & $\begin{array}{c}\text { Hipótese } \\
\text { nula }\end{array}$ & $\begin{array}{c}\text { Estatística } \\
\text { do teste } \\
(\lambda \text { max) }\end{array}$ & $\begin{array}{c}\text { Valor } \\
\text { crítico } \\
5 \%\end{array}$ & $\begin{array}{c}\text { Valor } \\
\text { crítico } \\
1 \%\end{array}$ & $\begin{array}{c}\text { Hipótese } \\
\text { nula }\end{array}$ & $\begin{array}{c}\text { Estatística } \\
\text { do teste } \\
\text { (Trace) }\end{array}$ & $\begin{array}{c}\text { Valor } \\
\text { crítico } \\
5 \%\end{array}$ & $\begin{array}{c}\text { Valor } \\
\text { crítico } \\
1 \%\end{array}$ \\
\hline 5 & $r=0$ & 70,06 & 34,40 & 39,79 & $r=0$ & 143,25 & 76,07 & 84,45 \\
\hline 4 & $r \leq 1$ & 41,00 & 28,14 & 33,24 & $r \leq 1$ & 73,19 & 53,12 & 60,16 \\
\hline 3 & $r \leq 2$ & 17,52 & 22,00 & 26,81 & $r \leq 2$ & 32,19 & 34,91 & 41,07 \\
\hline 2 & $r \leq 3$ & 10,39 & 15,67 & 20,20 & $r \leq 3$ & 14,67 & 19,96 & 24,60 \\
\hline 1 & $r \leq 4$ & 4,28 & 9,24 & 12,97 & $r \leq 4$ & 4,28 & 9,24 & 12,97 \\
\hline
\end{tabular}

Fonte: Resultados da pesquisa. Notas: Os valores críticos obtidos em Osterwald-Lenum (1992).

As defasagens consideradas para cada equação (série de preços) foram estimadas pelo teste AIC (AKAIKE). A inclusão das defasagens no modelo VEC é importante porque neste mercado prevalecem contratos a termo entre os segmentos, ou seja, as programações de compras, vendas e entregas são acordadas para diferentes períodos no tempo. O coeficiente estimado foi de $-1,1562$, sinalizando relação positiva de preços de fios sobre os de algodão 
(deve-se interpretar com sinal invertido), com nível de significância de 1\%. O que significa que quando o mercado de fios está aquecido aumenta a demanda por algodão, impactando positivamente os preços ao produtor, e vice-versa.

Em seguida, analisa-se a decomposição da variância do erro de previsão para cada série de preços, considerando-se doze períodos (meses). Na Tabela 4 analisa-se a decomposição para os preços de algodão em pluma. Observa-se que, aproximadamente, $90 \%$ da variância do erro de previsão do preço do algodão são decorrentes de choques nos preços da própria pluma, sendo o restante dependente praticamente da relação com os preços dos fios. A influência dos preços dos fios sobre os da pluma praticamente não se altera no período considerado dos choques. Os preços do algodão em pluma apresentam impactos dos estoques do produto em nível mundial (Coleman \& Thigpen, 1991), assim como os preços internos sofrem choque dos preços do próprio produto no cenário externo (Alves \& Ferreira Filho, 2006; Ferreira Filho \& Alves, 2006).

Da mesma forma, cerca de $85 \%$ da variância do erro de previsão do preço dos fios são decorrentes de choques nos preços dos próprios fios no segundo período, sendo o restante explicado pelo preço do algodão em pluma (Tabela 5). Os preços do algodão em pluma apresentam maior impacto sobre os preços de fios do que os de fios sobre os preços do algodão, mas a relação ainda é relativamente baixa, justificada pelos diferentes tipos de fios que podem ser produzidos, incluindo fibras artificiais e sintéticas.

Já os preços de tecelagem têm $84 \%$ de sua variância do erro de previsão decorrentes de choques em seus próprios preços, havendo também participações de fios e de algodão em pluma, mesmo que pequenas (Tabela 6). A autodependência histórica dos preços do próprio produto, observada em períodos anteriores, é equivalente à observada nos preços da pluma e dos fios.

As outras duas séries avaliadas se mostram menos dependentes das demais séries estudadas. No segundo período, $93 \%$ da variância do erro de previsão do preço dos vestuários são decorrentes de choques nos preços do próprio vestuário, sendo os preços de fios a outra variável com ligeira relação (Tabela 7). Para o IPCA, no terceiro período, 95\% de sua variância do erro de previsão são decorrentes de choques no próprio IPCA roupas (Tabela 8). Observa-se, portanto, que as variáveis consideradas no modelo apresentam pouca relação entre si, especialmente com o IPCA roupas. Dessa forma, aparentemente devem ser implementadas ações setoriais visando melhor o desempenho, uma vez que políticas para a cadeia como um todo podem não gerar os benefícios agregados esperados.

Tabela 4. Decomposição da variância do erro de previsão para os preços de algodão em pluma

\begin{tabular}{ccccccc} 
& \multirow{2}{*}{ Meses } & Desvio & \multicolumn{5}{c}{ Decomposição da variância devida a choques em \% } \\
\cline { 3 - 6 } & padrão & Algodão & Fios & Tecelagem & Vestuário & IPCA \\
\hline 1 & 0,0614 & 89,676 & 10,324 & 0,000 & 0,000 & 0,000 \\
2 & 0,0629 & 89,148 & 10,791 & 0,039 & 0,013 & 0,009 \\
3 & 0,0630 & 89,120 & 10,813 & 0,041 & 0,017 & 0,009 \\
4 & 0,0630 & 89,118 & 10,814 & 0,042 & 0,017 & 0,009 \\
5 & 0,0630 & 89,118 & 10,814 & 0,042 & 0,017 & 0,009 \\
6 & 0,0630 & 89,118 & 10,814 & 0,042 & 0,017 & 0,009 \\
7 & 0,0630 & 89,118 & 10,814 & 0,042 & 0,017 & 0,009 \\
8 & 0,0630 & 89,118 & 10,814 & 0,042 & 0,017 & 0,009 \\
9 & 0,0630 & 89,118 & 10,814 & 0,042 & 0,017 & 0,009 \\
10 & 0,0630 & 89,118 & 10,814 & 0,042 & 0,017 & 0,009 \\
11 & 0,0630 & 89,118 & 10,814 & 0,042 & 0,017 & 0,009 \\
12 & 0,0630 & 89,118 & 10,814 & 0,042 & 0,017 & 0,009 \\
\hline
\end{tabular}

Fonte: Resultados da pesquisa. 
Tabela 5. Decomposição da variância do erro de previsão para os preços de fios

\begin{tabular}{ccccccc|} 
Meses & Desvio & \multicolumn{5}{c}{ Decomposição da variância devida a choques em \% } \\
\cline { 3 - 7 } & padrão & Algodão & Fios & Tecelagem & Vestuário & IPCA \\
\hline 1 & 0,0171 & 0,000 & 100,000 & 0,000 & 0,000 & 0,000 \\
2 & 0,0198 & 13,578 & 85,516 & 0,282 & 0,597 & 0,027 \\
3 & 0,0202 & 15,812 & 83,230 & 0,273 & 0,659 & 0,026 \\
4 & 0,0202 & 16,033 & 83,000 & 0,275 & 0,665 & 0,026 \\
5 & 0,0202 & 16,048 & 82,984 & 0,275 & 0,666 & 0,026 \\
6 & 0,0202 & 16,049 & 82,983 & 0,275 & 0,666 & 0,026 \\
7 & 0,0202 & 16,049 & 82,983 & 0,275 & 0,666 & 0,026 \\
8 & 0,0202 & 16,049 & 82,983 & 0,275 & 0,666 & 0,026 \\
9 & 0,0202 & 16,049 & 82,983 & 0,275 & 0,666 & 0,026 \\
10 & 0,0202 & 16,049 & 82,983 & 0,275 & 0,666 & 0,026 \\
11 & 0,0202 & 16,049 & 82,983 & 0,275 & 0,666 & 0,026 \\
12 & 0,0202 & 16,049 & 82,983 & 0,275 & 0,666 & 0,026 \\
\hline
\end{tabular}

Fonte: Resultados da pesquisa.

Tabela 6. Decomposição da variância do erro de previsão para os preços de tecelagem

\begin{tabular}{ccccccc} 
& \multirow{2}{*}{ Meses } & Desvio & \multicolumn{5}{c}{ Decomposição da variância devida a choques em \% } \\
\cline { 3 - 7 } & padrão & Algodão & Fios & Tecelagem & Vestuário & IPCA \\
\hline 1 & 0,0088 & 0,000 & 0,000 & 100,000 & 0,000 & 0,000 \\
2 & 0,0094 & 4,323 & 6,413 & 86,450 & 0,118 & 2,696 \\
3 & 0,0095 & 5,302 & 7,145 & 84,617 & 0,127 & 2,809 \\
4 & 0,0095 & 5,463 & 7,241 & 84,356 & 0,127 & 2,813 \\
5 & 0,0095 & 5,486 & 7,253 & 84,321 & 0,127 & 2,813 \\
6 & 0,0095 & 5,489 & 7,254 & 84,317 & 0,127 & 2,813 \\
7 & 0,0095 & 5,490 & 7,254 & 84,317 & 0,127 & 2,813 \\
8 & 0,0095 & 5,490 & 7,254 & 84,317 & 0,127 & 2,813 \\
9 & 0,0095 & 5,490 & 7,254 & 84,317 & 0,127 & 2,813 \\
10 & 0,0095 & 5,490 & 7,254 & 84,317 & 0,127 & 2,813 \\
11 & 0,0095 & 5,490 & 7,254 & 84,317 & 0,127 & 2,813 \\
12 & 0,0095 & 5,490 & 7,254 & 84,317 & 0,127 & 2,813 \\
\hline
\end{tabular}

Fonte: Resultados da pesquisa.

Tabela 7. Decomposição da variância do erro de previsão para os preços de vestuários

\begin{tabular}{ccccccc} 
& & \multicolumn{5}{c}{ Decomposição da variância devida a choques em \% } \\
\cline { 3 - 7 } Meses & $\begin{array}{c}\text { Desvio } \\
\text { padrão }\end{array}$ & Algodão & Fios & Tecelagem & Vestuário & IPCA \\
\hline 1 & 0,0068 & 0,000 & 0,000 & 0,000 & 100,000 & 0,000 \\
2 & 0,0070 & 0,035 & 4,115 & 1,963 & 93,278 & 0,610 \\
3 & 0,0071 & 1,061 & 5,547 & 2,019 & 90,592 & 0,781 \\
4 & 0,0072 & 1,407 & 5,767 & 2,010 & 90,019 & 0,797 \\
5 & 0,0072 & 1,464 & 5,792 & 2,008 & 89,938 & 0,798 \\
6 & 0,0072 & 1,471 & 5,795 & 2,008 & 89,929 & 0,798 \\
7 & 0,0072 & 1,471 & 5,795 & 2,008 & 89,928 & 0,798 \\
8 & 0,0072 & 1,471 & 5,795 & 2,008 & 89,928 & 0,798 \\
9 & 0,0072 & 1,471 & 5,795 & 2,008 & 89,928 & 0,798 \\
10 & 0,0072 & 1,471 & 5,795 & 2,008 & 89,928 & 0,798 \\
11 & 0,0072 & 1,471 & 5,795 & 2,008 & 89,928 & 0,798 \\
12 & 0,0072 & 1,471 & 5,795 & 2,008 & 89,928 & 0,798 \\
\hline
\end{tabular}

Fonte: Resultados da pesquisa. 
Tabela 8. Decomposição da variância do erro de previsão para os preços de roupas no varejo

\begin{tabular}{ccccccc} 
& Desvio & \multicolumn{5}{c}{ Decomposição da variância devida a choques em \% } \\
\cline { 3 - 7 } & padrão & Algodão & Fios & Tecelagem & Vestuário & IPCA \\
\hline 1 & 0,0062 & 0,000 & 0,000 & 0,000 & 0,000 & 100,000 \\
2 & 0,0064 & 2,463 & 0,425 & 0,032 & 1,493 & 95,587 \\
3 & 0,0065 & 3,184 & 0,437 & 0,054 & 1,683 & 94,641 \\
4 & 0,0065 & 3,227 & 0,441 & 0,063 & 1,701 & 94,569 \\
5 & 0,0065 & 3,227 & 0,445 & 0,064 & 1,702 & 94,562 \\
6 & 0,0065 & 3,227 & 0,447 & 0,064 & 1,702 & 94,560 \\
7 & 0,0065 & 3,228 & 0,447 & 0,064 & 1,702 & 94,560 \\
8 & 0,0065 & 3,228 & 0,447 & 0,064 & 1,702 & 94,560 \\
9 & 0,0065 & 3,228 & 0,447 & 0,064 & 1,702 & 94,560 \\
10 & 0,0065 & 3,228 & 0,447 & 0,064 & 1,702 & 94,560 \\
11 & 0,0065 & 3,228 & 0,447 & 0,064 & 1,702 & 94,560 \\
12 & 0,0065 & 3,228 & 0,447 & 0,064 & 1,702 & 94,560 \\
\hline
\end{tabular}

Fonte: Resultados da pesquisa.

Este resultado fica ainda mais evidente quando se avaliam os impactos sobre os demais preços de choques de preços de algodão em pluma, acumulados ao longo de 12 meses.

Conforme dados da Figura 4, choques de $10 \%$ de preços de algodão em pluma tendem a se manter ao longo de um ano, acumulando aumento de cerca de $2,7 \%$ no período. Os preços de fios também absorveriam cerca de $20 \%$ do choque de preços do algodão em pluma ao longo de um ano.

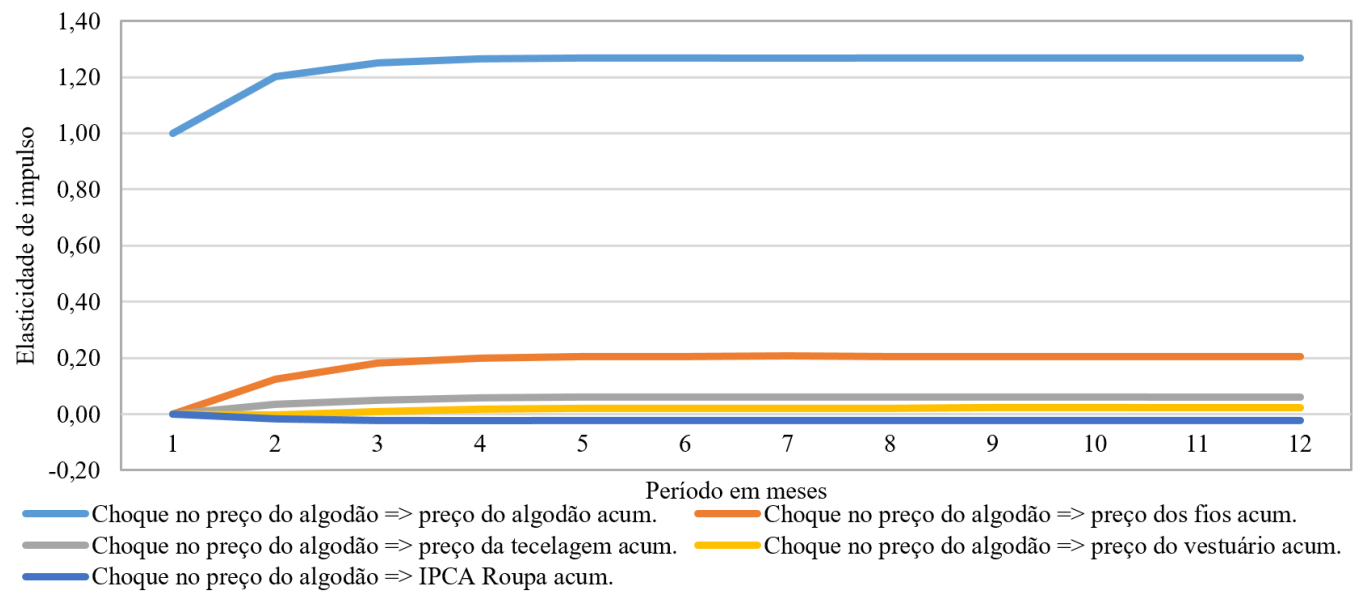

Figura 4. Função de impulso resposta acumulada do preço do algodão, de fios, de tecelagem, de vestuário e de roupas no varejo, devido a choques no preço do algodão em pluma. Fonte: Resultados da pesquisa.

Entretanto, a função de impulso resposta sinaliza que os preços de tecelagem, vestuário e de roupas no varejo praticamente não absorvem choques de preços do algodão em pluma. Esse resultado pode estar relacionado com o grande volume de manufaturados importados pelo país, em especial desde 2006, quando os valores das compras externas anuais superaram os das exportações. Entretanto, os preços de importações não se mostraram eficientes em modelo avaliado neste trabalho, ao contrário do esperado. Certamente este é um aspecto que merece mais investigações na cadeia agroindustrial do algodão no Brasil. 


\section{CONSIDERAÇÕES FINAIS}

Neste trabalho foi possível descrever o fluxo de transações na cadeia agroindustrial do algodão, através de revisão de literatura sobre o tema e da definição da estrutura de sistemas agroindustriais. Foram identificadas todas as etapas entre a compra de insumos, produção agrícola, processamento, usos industriais da fibra e do caroço de algodão, caracterizando as ramificações das transações entre elos das (agro)indústrias. Também foi possível descrever os usos do caroço de algodão e de fibrilha. Resumidamente, a pluma de algodão é o produto de maior valor mercadológico, sendo utilizada especialmente pela indústria têxtil. $\mathrm{Na}$ indústria têxtil, as fibras serão utilizadas pelas fiações, visando obter fios e filamentos. Esses produtos são encaminhados para as indústrias que realizam a tecelagem. $O$ elo seguinte são as indústrias de confecções, que fabricam os produtos para vestuários e acessórios, assim como para produtos dos segmentos de cama, mesa e banho. Os produtos finalizados são direcionados para os mercados atacadistas e/ou varejistas.

Tomando como base os preços de algodão em pluma, fios, tecelagem, vestuários e roupa, neste caso no mercado varejista, buscou-se identificar a direção, a intensidade e a velocidade de transmissão de choques nos preços da fibra de algodão sobre os preços de roupas ao consumidor final. Os resultados mostraram que os preços de algodão e fios apresentam certa inter-relação, mas tecelagem, vestuário e roupas são pouco relacionados com as demais séries de preços, e as variâncias de preços são explicadas em mais de 3/4 pelos próprios preços dos produtos. Com isso, choques de preços sofridos pelo algodão em pluma praticamente não impactam nas tendências de preços de produtos da cadeia têxtil, com exceção dos fios.

No geral, este estudo teve a contribuição de detalhar as ramificações da cadeia agroindustrial do algodão, com foco nas transações da pluma na cadeia têxtil, e também a transmissão de preços entre os produtos originados entre os elos dessa cadeia. Entende-se que a pouca inter-relação de preços do algodão com os preços dos demais produtos da cadeia têxtil é resultado dos expressivos volumes e valores das importações de manufaturados. Certamente trabalhos que consigam inserir variáveis relacionadas ao mercado externo podem trazer novas contribuições a esta área de estudo.

\section{REFERÊNCIAS}

Akil, H. M., Omar, M. F., Mazuki, A. A. M., Safiee, S., Ishak, Z. A. M., \& Abu Bakar, A. (2011). Kenaf fiber reinforced composites: a review. Materials \& Design, 32(8-9), 4107-4121. http://dx.doi.org/10.1016/j.matdes.2011.04.008

Alves, L. R. A. (2006). A reestruturação da cotonicultura no Brasil: fatores econômicos, institucionais e tecnológicos (Tese de doutorado), Escola Superior de Agricultura "Luiz de Queiroz". Recuperado em 19 de setembro de 2019, de http://icepea.esalq.usp.br/pdf/Tese_doutorado_Lucilio.pdf

Alves, L. R. A., \& Ferreira Filho, J. B. S. (2006). Inter-relações de preços dos mercados interno e externo de algodão em pluma. Revista GEPEC, 10(1), 71-92. Recuperado em 19 de setembro de 2019, de http://e-revista.unioeste.br/index.php/gepec/article/view/374/285

Alves, L. R. A., Barros, G. S. C., \& Bacchi, M. R. P. (2008). Produção e exportação de algodão: efeitos de choques de oferta e de demanda. Revista Brasileira de Economia, 62(4), 381-405. http://dx.doi.org/10.1590/S0034-71402008000400002

Alves, L. R. A., Lima, F. F., \& Ferreira Filho, J. B. S., \& Braghetta, M. A. S. (2018). Estrutura de mercado e formação de preços na cadeia produtiva do algodão. In L. R. A. Alves \& C. J. C. Bacha (Eds.), Panorama da agricultura brasileira: estrutura de mercado, comercialização, formação de preços, custos de produção e sistemas produtivos (1. ed., pp. 177-217). Campinas: Alínea. Recuperado em 19 de setembro de 2019, de http://www.grupoatomoealinea.com.br/panorama-da-agricultura-brasileiraestrutura-de-mercado-comercializacao-formacao-de-precos-custos-de-producao-e-sistemasprodutivos.html

Associação Brasileira da Indústria Têxtil e de Confecção - ABIT. (2013). Indústria têxtil e de confecção brasileira: cenários, dasafios, perspectivas e demandas. Cartilha. Brasília. Recuperado em 19 de setembro de 2019, de http://www.abit.org.br/conteudo/links/publicacoes/cartilha_rtcc.pdf

Associação Brasileira de Produtores de Fibras Artificiais e Sintéticas - ABRAFAS. (2019). Recuperado em 22 de setembro de 2019, de http://www.abrafas.org.br/site/vitrine-

noticias/index/materia/estatisticas-/c/b6e 
Barbosa, M. Z. (1996). Transformacao do mercado brasileiro de algodao e a influência de políticas comerciais. Informações Econômicas, 26(2), 11-23. Recuperado em 19 de setembro de 2019, de http://www.iea.sp.gov.br/ftpiea/ie/1996/tec1-0296.pdf

Barbosa, M. Z., Margarido, M. A., \& Nogueira Junior, S. (2002). Análise da elasticidade de transmissão de preços no mercado brasileiro de algodão. Nova Economia, 12(2), 79-108. Recuperado em 19 de setembro de 2019 , de http://revistas.face.ufmg.br/index.php/novaeconomia/article/viewFile/402/406

Bevilacqua, M., Ciarapica, F. E., Mazzuto, G., \& Paciarotti, C. (2014). Environmental analysis of a cotton yarn supply chain. Journal of Cleaner Production, 82, 154-165. http://dx.doi.org/10.1016/j.jclepro.2014.06.082

Brasil. Ministério da Agricultura Pecuária e Abastecimento. Secretaria de Política Agrícola. Instituto Interamericano de Cooperação para a Agricultura. (2007). Cadeia produtiva do algodão. Brasília: IICA : MAPA/SPA. Recuperado em 19 de setembro de 2019, de http://www.iica.org.br/Docs/CadeiasProdutivas/Cadeia Produtiva do Algodão.pdf

Brasil. Ministério da Indústria, Comércio Exterior e Serviços - MDIC. Secretaria de Comércio Exterior SECEX. (2019). Análise das Informações de Comércio Exterior - Comex Stat Web. Recuperado em 15 de setembro de 2019, de http://comexstat.mdic.gov.br/pt/home

Brasil. Ministério da Indústria, Comércio Exterior e Serviços - MDIC. (2020). Comex Stat. Recuperado em 20 de agosto de 2020, de http://comexstat.mdic.gov.br/pt/home

Buainain, A. M., \& Sousa Filho, H. M. (2008). Metodología para estudo das relações de mercado em sistemas agroindustriais. Brasília: IICA.

Castro, N. R., Alves, L. R. A., Lima, F. F., \& Giachini, G. F. (2017). Análise do padrão de crescimento do valor bruto da produção cotonícola no Brasil entre 1995 e 2015: uma aplicação do modelo shiftshare. Organizações Rurais \& Agroindustriais, 19(4), 304-321. http://dx.doi.org/10.21714/2238$68902017 v 19 n 4 p 304$

Coelho, A. B. (2004). A cultura do algodão e a questão da integração entre preços internos e externos. Revista de Economia e Sociologia Rural, 42(1), 153-169. http://dx.doi.org/10.1590/S010320032004000100008

Coleman, J., \& Thigpen, M. E. (1991). An econometric model of the world cotton and non-cellulosic fibers markets (World Bank Staff Commodity Working Paper, No. 24). Washington, D.C. Recuperado em 19 de setembro de 2019, de http://documents.worldbank.org/curated/pt/668141468766790899/pdf/multi-page.pdf

Companhia Nacional de Abastecimento - CONAB. Portal de Informações Agropecuárias. (2019). Quadro de oferta e demanda. Recuperado em 19 de setembro de 2019, de https://portaldeinformacoes.conab.gov.br/index.php/oferta/oferta-dashboard

Costa, A. C. R., \& Rocha, E. R. P. (2009). Panorama da cadeia produtiva têxtil e de confecções e a questão da inovação. BNDES Setorial, 29, 159-202. Recuperado em 19 de setembro de 2019, de http://www.bndes.gov.br/bibliotecadigital

Costa, S. R., \& Bueno, M. (2004). A saga do algodão: das primeiras lavouras à ação na OMC (1. ed.). Rio de Janeiro: Insight Engenharia de Comunicação.

Cruz, M. S., \& Maia, S. F. (2008). Desempenho da cotonicultura brasileira pós-abertura econômica. Revista Economica do Nordeste, 39(2), 263-284. Recuperado em 19 de setembro de 2019, de http://www.bnb.gov.br/projwebren/exec/artigoRenPDF.aspx?cd_artigo_ren=1084

Desrochers, P., \& Szurmak, J. (2017). Long distance trade, locational dynamics and by-product development: insights from the history of the american cottonseed industry. Sustainability, 9(4), 579. http://dx.doi.org/10.3390/su9040579

Dias, M. D. C. (2014). A cadeia produtiva têxtil mundial: uma abordagem a partir do conceito de cadeias produtivas globais. Revista Gestão \& Conexões Management, 3(2), 156-180. http://dx.doi.org/10.13071/regec.2317-5087.2014.3.2.8303.156-180.

Elliott, G., Rothenberg, T. J., \& Stock, J. H. (1996). Efficient tests for an autoregressive unit root. Econometrica, 64(4), 813-836. http://dx.doi.org/10.2307/2171846

Enders, W. (2014). Applied econometric time series (4th ed.). New Jersey: John Wiley Sons. Recuperado em 19 de setembro de 2019, de https://www.wiley.com/enbr/Applied+Econometric+Time+Series,+4th+Edition-p-9781118808566

Engle, R. F., \& Granger, C. W. J. (1987). Co-integration and error correction: representation, estimation, and testing. Econometrica, 55(2), 251-276. http://dx.doi.org/10.2307/1913236 
Farina, E. M. M. Q. (1999). Competitividade e coordenação de sistemas agroindustriais: um ensaio conceitual. Gestão \& Produção, 6(3), 147-161. http://dx.doi.org/10.1590/S0104-530X1999000300002

Ferreira Filho, J. B. S., \& Alves, L. R. A. (2006). Preços do algodão sofrem maior influência do exterior. Revista Visão Agrícola, 6, 132-137. Recuperado em 19 de setembro de 2019, de http://www.esalq.usp.br/visaoagricola/edicoes/algodao

Ferreira Filho, J. B. S., Alves, L. R. A., \& del Villar, P. M. (2009). Estudo da competitividade da produção de algodão entre Brasil e Estados Unidos - safra 2003/04. Revista de Economia e Sociologia Rural, 47(1), 59-88. http://dx.doi.org/10.1590/S0103-20032009000100003

Freire, E. C., Moreira, J. A. N., \& Medeiros, L. C. (1980). Contribuição das ciências agrárias para o desenvolvimento: o caso do algodão. Revista de Economia e Sociologia Rural, 18(3), 383-413. Recuperado em 19 de setembro de 2019, de http://www.revistasober.org/journal/resr/article/5d0776bb0e8825403ff70b6c

Fundação Getúlio Vargas - FGV. Instituto Brasileiro de Economia - IBRE. (2018). Recuperado em 15 de dezembro de 2018, de http://www14.fgv.br/autenticacao_produtos_licenciados/default.aspx

Gonçalves, J. S. (1997). Crise do algodão brasileiro pos-abertura dos anos 90 e as condicionantes da retomada da expansão em bases competitivas. Informações Econômicas, 27(3). Recuperado em 15 de dezembro de 2018, de http://www.iea.sp.gov.br/ftpiea/ie/1997/tec1-0397.pdf

Instituto de Estudos e Marketing Industrial-IEMI. (2018). Brasil têxtil 2018: relatório setorial da indústrial têxtil brasileira. São Paulo: IEMI. Recuperado em 15 de dezembro de 2018, de https://www.abit.org.br/cont/brasil-textil-2018-login

Johansen, S. (1988). Statistical analysis of cointegration vectors. Journal of Economic Dynamics \& Control, 12(2-3), 231-254. http://dx.doi.org/10.1016/0165-1889(88)90041-3

Johansen, S., \& Juselius, K. (1990). Maximum likelihood estimation and inference on cointegration with applications to the demand for money. Oxford Bulletin of Economics and Statistics, 52(2), 169210. http://dx.doi.org/10.1111/j.1468-0084.1990.mp52002003.x

Jonker, J., \& Pennink, B. (2010). The essence of research methodology: a concise guide for master and PhD students in management science. Berlin: Springer. https://doi.org/10.1007/978-3-540-71659-4.

Kwiatkowski, D., Phillips, P. C. B., Schmidt, P., \& Shin, Y. (1992). Testing the null hypothesis of stationarity against the alternative of a unit root: how sure are we that economic time series have a unit root? Journal of Econometrics, 54(1-3), 159-178. http://dx.doi.org/10.1016/0304-4076(92)90104-Y

Martin, M. (2014, January 15). Global supply chains: deciding the way forward. Supply Chain News.. Recuperado em 15 de setembro de 2019, de https://www.supplychain247.com/article/global_supply_chains_deciding_the_way_forward

Neves, M. F., \& Pinto, M. J. A. (2012). A cadeia do algodão brasileiro: desafios e estratégias - ABRAPA biênio 2011/12. Brasília. Recuperado em 15 de setembro de 2019, de https://www.abrapa.com.br/Bibliotecalnstitucional/Publicações/Livros/Livro A Cadeia do Algodao Abrapa.pdf

Osterwald-Lenum, M. (1992). A note with quantiles of the asymptotic distribution of the maximum likelihood cointegration rank test statistics. Oxford Bulletin of Economics and Statistics, 54(3), 461 472. http://dx.doi.org/10.1111/j.1468-0084.1992.tb00013.x

Ozturk, O. (2017). Effects of price transmission and exchange rate elasticities of three developing countries on the world cotton trade. Applied Economics and Finance, 5(1), 91-101. http://dx.doi.org/10.11114/aef.v5i1.2894

Pan, S., Mohanty, S., Ethridge, D., \& Fadiga, M. (2006). The impacts of U.S. cotton programs on the world market: an analysis of Brazilian WTO petition. Journal of Cotton Science, 10, 180-192. Recuperado em 15 de setembro de 2019, de http://journal.cotton.org/journal/2006-10/3/upload/jcs10-180.pdf

Perveen, S., \& Arsalan, M. H. (2014). A review of potential use of geo-information technologies for cotton supply chain management. International Journal of Biodeversity and Conservation, 6(10), 724734. http://dx.doi.org/10.5897/JJBC2010.081.

Rochelle, T. C. P., \& Ferreira Filho, J. B. S. (1999). Função de custo translog e o mercado de fatores para o algodão no Estado de São Paulo: o caso da DIRA de Campinas. Revista de Economia e Sociologia Rural, 37(2), 77-96. Recuperado em 15 de setembro de 2019, de http://www.revistasober.org/journal/resr/article/5d9635590e8825e71f2bac34

Sanjay, M. R., Madhu, P., Jawaid, M., Senthamaraikannan, P., Senthil, S., \& Pradeep, S. (2018). Characterization and properties of natural fiber polymer composites: a comprehensive review. Journal of Cleaner Production, 172, 566-581. http://dx.doi.org/10.1016/j.jclepro.2017.10.101 
United States Department of Agriculture - USDA. (2019). Foreign Agricultural Service. Recuperado em 9 de abril de 2019, de https://apps.fas.usda.gov/psdonline/app/index.html\#/app/home

Universidade de São Paulo - USP. Escola Superior de Agricultura "Luiz de Queiroz"- ESALQ, Centro de Estudos Avançados em Economia Aplicada - CEPEA. (2019). Algodão. Recuperado em 28 de janeiro de 2019, de https://www.cepea.esalq.usp.br/br/indicador/algodao.aspx

Van Tot, B. (2014). Textile \& apparel industry report: opportunities for breakthrough. Recuperado em 28 de janeiro de 2019, de http://fpts.com.vn/FileStore2/File/2014/07/01/Textile and Apparel Industry Report (latest).pdf

Zylbersztajn, D. (2000). Conceitos gerais, evolução e apresentação do sistema agroindustrial. In D. Zylbersztajn \& M. F. Neves (Eds.), Economia e gestão dos negócios agroalimentares: indústria de alimentos, indústria de insumos, produção agropecuária, distribuição (pp. 1-21). São Paulo: Pioneira Thomson Learning.

Submetido: $7 / j a n / 2020$

Aceito: $2 /$ nov/2020

JEL CLASSIFICATION: C32; E31; M31; 013; Q11. 